\title{
Renin-angiotensin-aldosterone system inhibitors - a realm of confusion in COVID-19
}

\author{
Angela Madalina Lazar ${ }^{1 *}$
}

\begin{abstract}
Currently, there is a persisting dispute regarding the renin-angiotensin-aldosterone-system (RAAS) inhibitors' safety of use in COVID-19 pandemics. On one side, RAAS inhibitors appear to determine an overexpression of ACE2, the receptor of SARS-CoV-2. Therefore, they could increase the risk of SARS-CoV-2 infection and its degree of severity. On the other side, the discontinuation of RAAS leads to cardiovascular decompensation and has been discouraged by the major medical societies. Also, large-cohort studies report beneficial or at least neutral effects for the RAAS inhibitors in COVID-19 patients. Worldwide, millions of patients receive RAAS inhibitors for the treatment of hypertension and other important comorbidities. In this context, knowledge of the exact effect of these medications becomes of crucial significance. This paper aims to fill in a gap in the current knowledge and presents a putative mechanism by which RAAS inhibitor administration's beneficial results can be explained better. RAAS inhibitors can be beneficial, as they counteract the excessive detrimental activation of the classical angiotensin-converting enzyme (ACE) axis, decreasing the angiotensin II levels. The angiotensin receptor blockers (ARBs) increase the angiotensin II levels, while the angiotensin-converting enzyme inhibitors (ACEI) increase the angiotensin I levels; these substrates will compete with the SARS-CoV-2 for the ACE2 binding, decreasing the viral infectivity. In addition, following the RAAS inhibitors treatment, the up-regulated ACE2 will cleave these substrates (angiotensin I and II), particularly to angiotensin 1-7 that possesses vasodilator, protective effects.
\end{abstract}

Keywords: SARS-CoV-2, COVID-19, Renin-Angiotensin System, Angiotensin-Converting Enzyme Inhibitors, Angiotensin Receptor Blockers, ACE2, hypertensive medication, safety, Romania

\section{Background}

The current COVID-19 pandemic has already made 2,974,642 deaths globally, as reported by the World Health Organization (WHO) on 16th April 2021 [1]. Although more than one year has passed since the initial burst of the SARS-CoV-2 pandemics and the associated high rates of infectivity, morbidity, and mortality [2], there is still no definitive specific and effective therapy for this type of coronavirus infection [3]. Even more, because of the SARS-CoV-2 genomic mutations, the achievement of a vaccine for all the viral strains becomes extremely difficult, and we can face more and more repeated COVID-19 pandemics waves $[4,5]$. The limitations in the prevention and therapeutic management of COVID-19 are explainable through the many current gaps existing in our knowledge of the SARS-CoV-2 mechanism of infectivity, transmissibility, and differences to other previous coronaviruses. In this context, it is not surprising to discover

*Correspondence: angelalazar.2008@yahoo.com

${ }^{1}$ Department of Functional Sciences, University of Medicine and Pharmacy "Carol Davila" Bucharest, Romania.

Full list of author information is available at the end of the article that the SARS-CoV-2 infection has become a realm of controversies, where nothing is for sure yet. The origin and transmissibility routes across species are still unclear; even an insect-vector-dissemination for SARS-CoV-2 across species and other putative types of inter-human transmissibility than those already described have been suggested [4]. Also, there is insufficient knowledge of the precise protease/sheddase to activate the SARS-CoV-2 for host cell entry and the pathogenic mechanisms explaining viral cell syncytia formation $[4,6]$. The exact intervention of the immune system in the SARS-CoV-2 infection still holds many mysteries, as the titer of antibodies developed by the infected individuals is so variable, and the protective titer has not been defined yet. Even more, SARSCoV-2 appears to hoax the immune cell and even to elicit an "antibody-dependent cell entry," as described by some authors [7]. In this realm of uncertainties and controversies, a single question remains open: when will the pandemics end? However, in the absence of an answer, we must find strategies to survive, gain valid knowledge on SARS-CoV-2 and develop efficient prevention methods and therapies to address future putative re-bursts of coronaviruses pandemics [8]. 


\section{Controversies regarding the RAAS inhibitors}

The COVID-19 pandemics has also brought many concerns and contradictory findings from the scientific community regarding the possible effects and safety of the renin-angiotensinaldosterone system (RAAS inhibitors) (angiotensin-converting enzyme inhibitors (ACEI) and angiotensin II receptor blockers (ARB)) in SARS-CoV-2 infected patients [9]. It is suspected that ACEI and ARB may increase the risk of infection and lead to more severe forms of the disease [10-14]. As there are millions of patients treated with these medication classes, understanding their exact effects in the context of the SARSCoV-2 infection becomes crucial. On one side, RAAS inhibitors are considered to determine an up-regulation of membrane ACE2 receptors that might increase the risk of SARS-CoV-2 infectivity in the treated patients (as ACE2 are the receptor for the SARS-CoV-2) [12,15-19]. On the other hand, RAAS inhibitors increase the angiotensin II levels, with apparent undesired effects, as it has vasoconstrictive, proinflammatory, and pro-hypertrophic effects [20]. Following ACEI/ARB therapy, the increase in the angiotensin II level is secondary, by accumulation, and feedback increases in the renin levels and novel production via non-ACE pathways [21].

Currently, it is acknowledged that certain categories of patients are at increased risk of SARS-CoV-2 infection and of developing more severe forms of the disease. Such categories are older, hypertensive, male patients, diabetes, chronic kidney, and cardiovascular disease. The same categories of patients are also known to receive more frequent medication, including ACEI/ARBs [18, 19, 22, 23]. Therefore, understanding the exact effects and mechanism of action of RAAS inhibitors becomes a matter of particular importance. However, COVID19 patients usually present multiple comorbidities. The discontinuity of the RAAS inhibitors in COVID-19 patients would be detrimental because it would lead to cardiac decompensation and death. Therefore, the discontinuity of the RAAS inhibitors was not recommended by the important medical societies (European Society of Cardiology Council, American Heart Association, American College of Cardiology). However, their exact role in SARS-CoV-2 infectivity remains tenebrous [24-29].

Findings from the reported studies on the RAAS inhibitors effects in COVID-19 patients

Many results come from Korean studies, as the world's first deidentified COVID-19 patient database is Korean [14]. Such an example is a large Korean retrospective observational cohort study on 7590 patients diagnosed with COVID-19, of which 1111 patients had RAAS inhibitors medication within six months before the infection, and 794 patients served as a comparator cohort. The study has shown that the use of RAAS inhibitors in COVID-19 patients was not associated with higher all-cause mortality when compared to other classes of antihypertensive drugs. Also, the study highlighted that replacing the RAAS inhibitors with other antihypertensive medication may increase the risk of cardiovascular events in certain categories of patients (patients with heart failure, chronic kidney disease, after acute myocardial infarction) [14]. Kim et al. [15] conducted a retrospective nationwide study in Korea on a group of 5707 patients with confirmed COVID-19 (from a cohort of 69793 subjects screened for COVID-19). The authors found that the use of ACEI/ARB was not statistically associated with poorer outcomes (all-cause mortality, respiratory events, need for ICU admission, the necessity for mechanical ventilation, the occurrence of sepsis) for COVID-19 patients when compared to non-users. In fact, on the contrary, the COVID-19 patients treated with ACEI/ARB for their comorbidities (hypertension, heart disease, renal diseases) had better clinical outcomes than the non-users. The ACEI/ARB users were more frequent than the non-users older, male patients, associating a history of comorbidities such as hypertension, hyperlipidemia, diabetes, cardiovascular, or kidney disease. Therefore, the better clinical outcome for the RAAS inhibitors users is even more interesting [15]. The finding of Kim et al. [15] is surprising as these comorbidities are usually associated with poorer outcomes for the COVID-19 patients [18, 30-33]. Similar beneficial results of RAAS inhibitors in COVID-19 have also been reported by other studies collecting data from Italy and the United States [10, 34, 35]. Therefore, the resulting conclusion from some of the performed clinical studies is that ACEI/ARB can be beneficial for COVID-19 patients with preexisting cardiovascular medication. Baral et al. [19] performed a systematic review on 40 trials selected out of 1031 studies from PubMed and Embase (the largest up-to-date). As a result of their extensive analysis, the authors reported a lower risk of severe/critical outcomes and death in hypertensive ARB/ACEI COVID-19 patients as opposed to non-ARB/non-ACEI users [19]. Therefore, the systematic review of Baral et al. [19] supports the use of RAAS inhibitors in COVID-19 patients. However, the authors of the review conclude that the exact role of these medications is still insufficiently understood.

The limitations of the analyzed studies explain the reserve in concern with a clear conclusion; most of them were observational, retrospective, with a lack in the randomized controlled studies [19]. However, some studies report mixed results. For example, an important study conducted on a cohort of Veterans with a history of hypertension treated with ACEI/ARB for at least two years or with other types of medications (control) has found that ACEI use was, in fact, significantly associated with a lower risk of a positive SARSCoV-2 test compared to non-users and ARB users.

Interestingly, the use of ACEI was significantly associated with a higher risk of hospitalization and mechanical ventilation compared to non-users or ARB users. The study of Li et al. [23] showed that neither ACEI nor ARB use was associated with increased mortality or other adverse events for the COVIDtreated patients than ACEI/ARB-non-users [23]. However, such an extensive study has some limitations: the majority of the patients (around 93\%) were male; the study did not consider the use of diuretics in the previous treatment of the patients and other sources of bias/confounder factors. Other studies have not described a direct beneficial effect regarding RAAS inhibitors' use. However, they reported no significant association between using this type of medication and increased susceptibility to SARS-CoV-2 infection or worse patient outcomes, arguing against ACEI/ARB discontinuation [11, 36, 37]. Nonetheless, another study, a randomized trial of 699 patients with moderateand severe forms of COVID-19, with previous ACEI/ARB medication showed that ACEI/ARB discontinuation did not lead to a worse outcome compared to the group of patients that 
received a continuous ACEI/ARB administration [13]. Altogether, the number of studies describing a neutral effect of ACEI/ARB is small [38]. However, no clinical studies reporting a significantly detrimental result of RAAS inhibitors in COVID-10 patients associating cardiovascular comorbidities could be found in the existing literature. Therefore, most of these studies' results are contrary to what was previously suspected, and the real mechanism by which these medications intervene in SARS-CoV-2 infection is only partially understood. There are still reports that remain inconclusive [23], and even the up-regulation of the ACE2 receptors in RAAS users is now questioned. In this regard, some studies have even started to question the frequency of the ACE2 overexpression after RAAS-inhibitors treatment or require additional evidence $[18,39]$. Other studies report inconsistent effects, where RAAS inhibitors increase, other times decrease, or even do not alter the ACE2 expression level [40]

Mechanisms by which RAAS inhibitors could be beneficial SARS-CoV-2 uses ACE2 receptors in order to enter the host cells. However, SARS-CoV-2 infection determines a downregulation of the membrane ACE2 [41] by multiple mechanisms. Also, increased angiotensin II levels per se (that occur in SARS-CoV-2 infection) appear to lead to an ACE2 receptor downregulation [40]. SARS-CoV-2 binding to the host cells leads to the activation and up-regulation of ADAM-17, an enzyme that determines the shedding of the full-length ACE2 receptors and the release of short, soluble ACE2 into the plasma. As a result, a downregulation of the membrane ACE2 ensues. Also, COVID-19 is associated with an important cytokine storm and oxidative stress that activate ADAM-17, leading to more ACE2 shedding and a loss in the membrane ACE2 receptors $[18,41]$. IL-4 and IFN-gamma are known to induce repression in the expression of the ACE2 mRNA. The decrease in the ACE2 leads to an accumulation of angiotensin II (Ag-II). Ag-II will activate the ERK-MAP kinase signaling pathway. The consequence will be activating ADAM-17 and a sustained feedback loop limiting ACE2 expression on the cell membranes. The death of the infected cells is another mechanism that contributes to the decrease in the ACE2 by loss; this decrease in the ACE2 expression will be followed by an unbalanced ACE axis activity [41]. The downregulation of the membrane ACE2 receptors is ensured by unbalance between the ACE and ACE2 [41]. Therefore, more angiotensin II will act on angiotensin II receptors (AT1 receptors) with vasoconstrictive, pro-inflammatory, pro-thrombotic, and pro-hypertrophic effects. Ag-II is known to induce the activation of nicotineamide adenine dinucleotide phosphate oxidase (NADPH) in endothelial and smooth muscle vascular cells, increasing the generation of reactive oxygen species that lead to cell injury and apoptosis. Ag-II also leads to detrimental lung fibrosis; it activates the p38 and p42/44 MAPK signaling pathways, followed by the proliferation of fibroblasts and lung fibrosis. Therefore, a decrease in ACE2 is followed by inflammation, cytokine storm, lung, and cardiac impairment [40, 41]. As a result, an increase in the ACE2 expression following RAAS inhibitors treatment could be beneficial, counteracting the excessive and damaging ACE axis with detrimental Ag-II accumulation $[18,41]$. ACE2 counteracts the effects of ACE as it converts the angiotensin II to angiotensin 1-7 (Ag 1-7) that is a vasodilator; it also converts angiotensin I to angiotensin 1-9 $[38,40]$. As ACEI decrease the levels of Ag-II, they also determine a beneficial decrease in the activation of ADAM-17, generation of oxygen free radicals by the lung macrophages, in the inflammatory response, the level of pro-inflammatory cytokines, the degree of cell injury and fibrosis [18, 40-42]. Therefore, RAAS inhibitors can be protective against lung injury. Also, as SARS-CoV-2 infection can lead to multiple organ injuries, including cardiac, the use of RAAS inhibitors could be additionally beneficial, as there are limited alternatives of effective cardiovascular medication [18, 41, 42].

In fact, the discontinuation of RAAS inhibitors in cardiovascular patients appears to increase morbidity and mortality among COVID-19 patients [43]. Some authors report that the anti-inflammatory effect of the RAAS inhibitors appears to be more pronounced in metabolic syndrome and aged rats [40]; this suggests a putative, more beneficial effect of this medication in more vulnerable groups of patients. It is known that ADAM-17 mediated shedding of ACE2 is essential for viral entry into the host cells. Therefore, a decrease in ADAM-17 activity following RAAS inhibitors treatment can reduce viral infectivity. That is why ADAM-17 inhibitors have already been proposed as antiviral treatment [40, 42]. Some studies also report a decrease in the TMPRSS2 expression following the ACEI, but not ARB's treatment. TMPRSS2 decreased levels can be another explanation for RAAS inhibitors' beneficial effects in COVID-19, as TMPRSS2 is an important enzyme in SARS-CoV-2 activation. Therefore, a decrease in TMPRSS2 will mean a decrease in the host cell infection [41].

Additional putative explanations for the mechanisms that underlie the beneficial effects of RAAS inhibitors in COVID-19 patients

Currently, despite the studies mentioned above, the effects and the exact mechanism by which ACEI/ARB intervenes in COVID-19 patients with cardiovascular diseases are still only partially understood. In 2020, Sommerstein et al. [9] launched a hypothesis suggesting that the RAAS inhibitors could increase the risk for SARS-CoV-2 infection and that of fatal outcomes $[14,38]$. Since then, the hypothesis has been insufficiently opposed by the limited, mostly retrospective, reported studies on the effects of RAAS inhibitors in COVID-19.

However, the conducted studies describe beneficial or neutral effects of this medication in COVID-19. Therefore, controversy regarding the effects of RAAS inhibitors in COVID-19 still persists. The finding that the ACE function is also essential for innate and adaptive immunity, playing a major role in fighting against infections and tumors, adds a supplementary level of confusion. ACE is expressed on immune cells, such as neutrophils and monocyte-macrophages, and was shown to play a key role as an important pro-inflammatory modulator. Its depletion was associated with an increased gravity of infections and tumor progression in mice [44, 45]. Therefore, we would expect that ACEI/ARB leads to a worse prognostic in COVID-19 patients; however, this "expectation" is contradicted by the reported beneficial results of the RAAS inhibitors in the COVID-19 patients, as well as reported in laboratory studies [19, 40, 42]. 


\section{Author's viewpoint}

The personal opinion expressed in the current paper is that RAAS inhibitors could be beneficial in SARS-CoV-2 disease by multiple mechanisms. ACEI and ARB could be beneficial as they increase the blood level of angiotensin II and I. The angiotensin-converting enzyme inhibitors (ACEI) prevent the action of the ACE enzyme that normally cleaves angiotensin I and leads to the formation of angiotensin II. Therefore, by blockage of the ACE, the potent vasoconstrictor angiotensin II levels will decrease while those of the angiotensin I increase. There are almost no scientific reports on the biological effects of angiotensin I per se. However, it is known to be a substrate for ACE2; ACE will cleave angiotensin I to angiotensin 1-9 that will act on AT2 receptors, with beneficial effects (vasodilator, anti-inflammatory, anti-thrombotic, anti-fibrotic effects). Also, the initial decrease in angiotensin II will lead to a feedback increase in renin levels followed by elevated levels of angiotensin II in patients chronically treated with ACEI [18, 21].

ACE is known to play a role in bradykinin conversion. ACEI will prevent this action, resulting in increased levels of bradykinin, with vasodilator effects in the treated patients [21, 22]. However, concerning bradykinin, ACEI could also be detrimental, as an increase in bradykinin levels could aggravate lung inflammation and contribute to shock development. However, by vasodilator action, bradykinin helps in improving organ blood flow. That is why it is regarded as protective in the case of COVID-19 hypertensive patients. Therefore, for the COVID-19 patients having cardiovascular comorbidities, the beneficial effects are considered to overpass the potential harm [41]. The angiotensin-receptor blockers (ARB) block the action of angiotensin II on its AT1 receptors, therefore preventing the vasoconstrictive, pro-inflammatory, pro-hypertrophic, and profibrosis effects of angiotensin II. The levels of angiotensin II will increase, but usually, it does not accumulate, as it becomes the substrate of other enzymes, such as ACE2. ACE2 converts angiotensin II into angiotensin 1-7 that acts on cell Mas receptors, with vasodilator, anti-inflammatory, and anti-fibrotic effects (opposite to angiotensin II) [18]. In this regard, a previous study from 2002 suggests that blocking ACE will potentially increase the level of activity of other enzymes involved in angiotensin I and bradykinin processing [22]. However, the authors did not name ACE2, its existence being a recent discovery at that time (in 2000) [46].

Anyway, Ferrario et al. have found that ACEI and ARBs determine a beneficial increase in ACE2 expression, Ag 1-7 levels, and decreased Ag-II level [47]. Moreover, long-term administration of ACEI is known to increase renin levels and associate increased levels of Angiotensin II produced in other tissues than the kidney [21]. More angiotensin II will mean more substrate for the ACE2. The increased levels of angiotensin II/angiotensin I generated by ACEI/ARB administration, as natural substrates, will compete with the SARS-CoV-2 for the ACE2 binding. As a result, ACE2 downregulation caused by SARS-CoV-2 binding to ACE2 receptors will be prevented/reduced, with positive outcomes for cardiovascular patients. There will be more ACE2 to cleave its natural substrates, angiotensin I and II; such cleavage will increase angiotensin 1-7 levels with vasodilator and antiinflammatory effects and a decrease in the vasoconstrictive, pro-inflammatory and pro-fibrotic effects of angiotensin II. An important aspect of being considered is that the SARS-CoV-2 infection leads to a downregulation of membrane ACE2 receptors. ACE2 enzyme converts angiotensin II to angiotensin 1-7 (with vasodilator, anti-inflammatory, and anti-hypertrophic effects) and angiotensin I to angiotensin 1-9, counteracting the effects of angiotensin II. Therefore, ACE2 downregulation would clearly be detrimental. The downregulation of the membrane ACE2 would explain why in patients with severe forms of COVID disease, angiotensin II levels are increased compared with healthy individuals. The increase in the angiotensin II levels will have a negative impact on the overall course of the disease [48]. In this regard, as ACEI/ARB leads to an upregulation of ACE2 expression [12], their final effect might be beneficial, contrary to what was originally suspected.

\section{Conclusion}

Worldwide, there are millions of patients treated with RAAS inhibitors. Therefore, knowledge of the RAAS inhibitor's mechanism of action, usefulness, safety, and effects in the context of the SARS-CoV-2 infection becomes of utmost importance. Future research should be done to assess the effects of ACEI/ARB on the circulating levels of angiotensin I, angiotensin II, angiotensin 1-7, angiotensin 1-9, bradykinin levels, membrane ACE2 expression (mRNA for ACE2) at different time points during their administration compared to ACEI/ARB non-users. An increased level of angiotensin 1-7 and 1-9 in the ACEI/ARB users would suggest a mechanism of action similar to that described by us. However, up to date, most of the performed studies have many limitations and are not internationally generalizable [11]. Therefore, caution should be taken in issuing concluding remarks, as the research remains open in the COVID realm of controversies.

\section{Abbreviation}

COVID-19: Coronavirus Disease 19; WHO: World Health Organization; SARS-CoV-2: Severe Acute Respiratory Coronavirus 2; RAAS inhibitors: Renin-AngiotensinAldosterone Inhibitors; ACEI: Angiotensin-Converting Enzyme Inhibitors; ARB: Angiotensin II Receptor Blockers; ACE2: Angiotensin-Converting Enzyme 2; ACE: AngiotensinConverting Enzyme; Angiotensin II: Ag-II; NADPH: NicotineAmide Adenine Dinucleotide Phosphate Oxidase.

\section{Declaration}

Acknowledgment

None.

\section{Funding}

The author received no financial support for the research, authorship, and/or publication of this article.

Availability of data and materials

Data will be available by emailing angelalazar.2008@yahoo.com

\section{Authors' contributions}

Angela Madalina Lazar (AML) is the principal investigator of this manuscript (Viewpoint). AML is the responsible author for the study concept, design, writing, reviewing, editing, and 
approving the manuscript in its final form. AML has read and approved the final manuscript.

Ethics approval and consent to participate

We conducted the research following the Declaration of Helsinki. However, Viewpoint Articles need no ethics committee approval.

\section{Consent for publication}

Not applicable

\section{Competing interest}

The author declare that she has no competing interest.

\section{Open Access}

This article is distributed under the terms of the Creative Commons Attribution 4.0 International License (http://creativecommons.org/licenses/by/4.0/), which permits unrestricted use, distribution, and reproduction in any medium, provided you give appropriate credit to the original author(s) and the source, provide a link to the Creative Commons license, and indicate if changes were made. The Creative Commons Public Domain Dedication

waiver (http://creativecommons.org/publicdomain/zero/1.0/) applies to the data made available in this article, unless otherwise stated.

\section{Author details}

${ }^{1}$ Department of Functional Sciences, University of Medicine and Pharmacy "Carol Davila" Bucharest, Romania.

\section{Article Info}

Received: 28 April 2021

Accepted: 02 July 2020

Published: 17 July 2021

\section{References}

1. World Health Organization (WHO). WHO Coronavirus (COVID19) Dashboard [cited 2021 April 16]. Available from https://covid19.who.int/

2. Jiang S, Du L, Shi Z. An emerging coronavirus is causing pneumonia outbreak in Wuhan, China: calling for developing therapeutic and prophylactic strategies. Emerging Microbes \& Infections 2020; 9 (1): 275-277. doi: 10.1080/22221751.2020.1723441.

3. Dehghani R and Kassiri H. A Brief Review on the Possible Role of Houseflies and Cockroaches in the Mechanical Transmission of Coronavirus Disease 2019 (COVID-19). Arch Clin Infect Dis 2020; 15(1):e97499. doi: 10.5812/archcid.102863.

4. Lazar AM. Understanding SARS-CoV-2 features of infectivity, aggressiveness, and transmissibility: an insect-vector theory for SARS-CoV-2 dissemination. Journal of Ideas in Health 2021; 4(Special 1): 343-347; https://doi.org/10.47108/jidhealth.Vol4.IssSpecial1.109.

5. Ali Jadoo SA. The second wave of COVID-19 is knocking at the doors: have we learned the lesson? Journal of Ideas in Health 2020; 3(Special 183-184. https://doi.org/10.47108/jidhealth.Vol3.IssSpecial1.72

6. Samavati L and Uhal BD. ACE2, Much More Than Just a Receptor for SARS-CoV-2. Frontiers in Cellular and Infection Microbiology 2020; 10:1-9; https:doi.org/103389/fcimb2020.00317.
7. Xia S, Liu M, Wang C, Xu W, Lan Q, Feng S, et al. Inhibition of SARS-CoV2 (previously 2019-nCoV) infection by a highly potent pan-coronavirus fusion inhibitor targeting its spike protein harbors a high capacity to mediate membrane fusion. Cell Research 2020; 30: 343-355. https://doi.org/10.1038/s41422-020-0305-X.

8. Ali Jadoo SA, Alhusseiny A, Yaseen S, Al-Samarrai M, Al-Rawi R, Al-Delaimy A, Abed M, Hassooni H. Knowledge, attitude, and practice toward COVID-19 among Iraqi people: a web-based cross-sectional study. Journal of Ideas in Health 2020; 3(Special2):258-65.

https://doi.org/10.47108/jidhealth.Vol3.IssSpecial\%202.59.

9. Sommerstein R, Kochen MM, Messerli FH, Gräni C. Coronavirus Disease 2019 (COVID-19): Do Angiotensin-Converting Enzyme Inhibitors/Angiotensin Receptor Blockers Have a Biphasic Effect? J Am Heart Assoc 2020; 9: e016509; DOI: 10.1161/JAHA.120.016509.

10. An J, Wai R, Zhou H, Luong TO, Gould MK, Mefford MT, et al. Angiotensin-Converting Enzyme Inhibitors or Angiotensin Receptor Blockers Use and COVID-19 Infection Among 824650 Patients With Hypertension From a US Integrated Healthcare System. J Am Heart Assoc 2021; 10(3): e0119669; doi:10.1161/JAHA.120.019669.

11. Morales DR, Conover MM, You SC, Pratt N, Kostka K, DuarteSalles $\mathrm{T}$, et al. Renin-angiotensin system blockers and susceptibility to COVID-19: an international, open science, cohort analysis. wwwthelancet.com/digital-health 2021; 3: e98-ee114.

12. Sriram K, Insel PA. Risks of ACE Inhibitor and ARB Usage in COVID-19: Evaluating the Evidence. Clinical Pharmacology \& Therapeutics 2020; 108(2): 236-241.

13. Lopes RD, Macedo AVS, de Barros E Silva PGM, MollBernardes RJ, dos Santos TM, Mazza L, et al. Effect of Discontinuing vs. Continuing angiotensin-converting enzyme inhibitors and angiotensin II receptor blockers on days alive and out of the hospital in patients admitted with COVID-19 A Randomized Trial. JAMA 2021; 325(3): 254-264.

14. Park J, Lee S-H, You SC, Kim J, Yang K. Effect of reninangiotensin-aldosterone system inhibitors on Covid-19 patients in Korea. Plos One 2021. https://doi.org/10.1371/journal.pone.0248058.

15. Kim JH, Baek YH, Lee H, Choe YJ, Shin HJ, Shin JY. Clinical outcomes of COVID-19 following the use of angiotensinconverting enzyme inhibitors or angiotensin-receptor blockers among patients with hypertension in Korea: a nationwide study. EpiH 2020; 43: e2021004; https://doi.org/10.4178/epih.e20211004.

16. Ferrario CM, Ahmad S, Groban L. Mechanisms by which angiotensin-receptor blockers increase ACE2 levels. Nature 2020; 17: 378; https://doi.org/10.1038/s41569-020-0387-7.

17. Gressens SB, Leftheriotis G, Dussaule JC, Flamant M, Levy BI, Vidal-Petiot E. Controversial Roles of Renin Angiotensin System and Its Modulators During the COVID-19 Pandemic. Frontiers in Physiology 2021; 12:624052; https://doi.org/10.3389/phys.2021.624052.

18. Parit R, Jajavel S. Association of ACE inhibitors and angiotensin type II blockers with ACE2 overexpression in COVID-19 comorbidities: A pathway-based analytical study. European Journal of Pharmacology 2021; 896: 173899. https://doi.org/10.1016/j.ejphar.2021.173899.

19. Baral R, White M, Vassiliou VS. Effect of Renin-AngiotensinAldosterone System Inhibitors in patients with COVID-19: a Systematic Review and Meta-analysis of 28,872 Patients. Current Atherosclerosis $\quad$ Reports 2020; 22: 61. https://doi.org/10.1007/s11883-020-00880-6.

20. Soler MJ, Ye M, Wysocki J, William J, Lloveras J, Battle D. Localization of ACE2 in the renal vasculature: amplification by 
angiotensin II type 1 receptor blockade using telmisartan. Am J Physiol Renal Physiol 2009; 296: F398-F405.

21. Barreras A, Gurk-Turner C. Angiotensin II receptor blockers. BUMC Proceedings 2003; 16:123-126.

22. Jackman HL, Massad MG, Sekosan M, Tan F, Brovkovych V, Marcic BM, et al. Angiotensin 1-9 and 1-7 Release in Human Heart. Role of Cathepsin A. Hypertension 2002; 39:976-981.

23. Li M, Wang Y, Ndiwane N, Orner MB, Palacios N, Mittler B, et al. The association of COVID-19 occurrence and severity with the use of angiotensin converting enzyme inhibitors or angiotensin-II receptor blocks in patients with hypertension. PLOS ONE 2021; 16(3): e0248652; https://doi.org/10.1371/journal.pone.0248652.

24. European Society of Cardiology (ESC). Position Statement of the ESC Council on Hypertension on ACE-inhibitors and angiotensin receptor blockers [Accessed on 17th April 2021]. Available from: https://www.escardio.org/Councils/Council-on-Hypertension (CHT)/News/position-statement-of-the-esc-council-onhypertension-on-ace-inhibitors-and-ang.

25. American College of Cardiology. HFSA/ACC/AHA statement addresses concerns. Re: using RAAS antagonists in COVID-19 [Accessed on 17th April 2021]; https://www.acc.org/latest-incardiology/articles/2020/03/17/08/59/hfsa-acc-aha-statementaddresses-concerns-re-using-raas-antagonists-in-covid-19.

26. Aronson JK. Drugs and the renin-angiotensin system in COVID19. BMJ.2020); 369: m1313.

27. Meng J, Xiao G, Zhang J, He X, Ou M, Bi J, et al. Reninangiotensin system inhibitors improve the clinical outcomes of COVID-19 patients with hypertension. Emerging Microbes \&Infections 2020; 9(1): 757-760.

28. Patel AB, Verma A. COVID-19 and Angiotensin-Converting Enzyme Inhibitors and Angiotensin Receptor Blockers. What is the Evidence? JAMA 2020; doi:10.1001/jama.2020.4812.

29. South AM, Tomlinson L, Edmonston D, Hiremath S, Sparks MA. Controversies of renin-angiotensin system inhibition during the COVID-19 pandemic. Nature Reviews. Nephrology 2020; https://doi.org/10.1038/s41581-020-0279-4.

30. Apicella M, Campopiano MC, Mantuano M, Mazoni L, Coppelli A, Del Prato S. COVID-19 in people with diabetes: understanding the reasons for worse outcomes. Lancet Diabetes Endocrinol 2020: 8; 782-92; https://doi.org/10.1016/S2213-8587(20)30238-2.

31. Rastad H, Ejtahed HS, Mahdavi-Ghorabi A, Arzaghi M, Safari A, Shahrestanaki E, et al. Factors associated with the poor outcomes in diabetic patients with COVID-19. J Diabetes Metab Disord 2020; 19: 1293-1302; https://doi.org/10.1007/s40200-020-006466.

32. Fang L, Karakiulakis G, Roth M. Are patients with hypertension and diabetes mellitus at increased risk for COVID-19 infection? The Lancet Respiratory Medicine 2020; 8 (4): e21; https://doi.org/10.1016/S2213-2600(20)30116-8.

33. Tadic M, Cuspidi C. The influence of diabetes and hypertension on outcome in COVID-19 patients: Do we mix apples and oranges? J Clin Hypertens 2021; 23: 235-237. https://doi.org/10.1111/jch.14145

34. Mancia G, Rea F, Ludergnani M, Apolone G, Corrao G. Reninangiotensin-aldosterone system blockers and the risk of Covid-19. N Engl J Med 2020; 382: 2431-2440.
35. Reynolds HR, Adikari S, Pulgarin C, Toxel AB, Itturate E, Johnson SB, et al. Renin-angiotensin-aldosterone inhibitors and risk of Covid-19. N Engl J Med 2020; 382: 2441-2448.

36. Hippisley-Cox J, Young D, Coupland C, Channon KM, Tan PS, Harrison DA, et al. Risk of severe COVID-19 disease with ACE2 inhibitors and angiotensin receptor blockers: cohort study including 8.3 million people. Heart 2020; 106(19):1503-1511; doi:10.1136/heartjnl-2020-317393.

37. Wang W, Zhao X, Wei W, Fan W, Gao K, He S, et al. Angiotensin-converting enzyme inhibitors or angiotensin receptor blockers (ARBs) may be safe for COVID-19 patients. BMC 2021; 21: 114; https://doi.org/10.1186/s12879-021-05821-5.

38. Shukla AK, banerjee M. Angiotensin-Converting-Enzyme 2 and Renin-Angiotensin System Inhibitors in COVID-19: An Update. High Blood Pressure\&Cardiovascular Prevention 2021. https://doi.org/10.1007/s40292-021-00439-9.

39. Kai H, Kai M, Niiyama H, Okina N, Sasaki M, Maeda T, et al. Overexpression of angiotensin-converting enzyme 2by reninangiotensin system inhibitors. Truth or myth? A systematic review of animal studies. Hypertension Research 2021; https://doi.org/10.1038/s41440-021-00641-1.

40. Pedrosa MA, Valenzuela R, Garrido-Gil P, Labandeira CM, Navarro G, Franco R et al. Experimental data using candesartan and captopril indicate no double-edged sword effect in COVID19. Clinical Science 2021; 135: 465-481. https://doi.org/10.1042/CS20201511.

41. Wang JJ, Edin ML, Zeldin DC, Li C, Wang DW, Chen C. Good or bad: Application of RAAS inhibitors in COVID-19 patients with cardiovascular comorbidities. Pharmacology \& Therapeutics 2020; 215: 107628. https://doi.org/10.1016/j.pharmthera.2020.107628.

42. Simko F, Baka T. Angiotensin-converting enzyme inhibitors and angiotensin II receptor blockers: potential allies in the COVID-19 pandemic instead of a threat? Clinical Science 2021; 135: 10091014. https://doi.org/10.1042/CS20210182.

43. Lou N. RAAS Inhibitors in COVID-19: A Signal of Benefit? [Accessed on 1st July 2021]. Available from: https://www.medpagetoday.com/infectiousdisease/covid19/86888.

44. Bernstein KE, Khan Z, Giani JF, Cao D-Y, Bernstein EA, Shen $X Z$. Angiotensin-converting enzyme in innate and adaptive immunity. Nat. Rev. Nephrol. 2018; 14(5): 325-336.

45. Cao D-Y, Saito S, Veiras LC, Okwan-Duodu D, Bernstein EA Giani JF, et al. Role of angiotensin-converting enzyme in myeloid cell immune responses. Cellular \& Molecular Biology Letters 2020; 25:31; https://doi.org/10.1186/s11658-020-00225-w.

46. Imai Y, Kuba K, Penninger JM. The discovery of angiotensinconverting enzyme 2 and its role in acute lung injury in mice. Exp. Physiol. 2008; 93(5):543-548; doi:10.1113/expphysiol.2007.040048.

47. Ferrario CM, Jessup J, Chapell MC, Acerill DB, Brosnihan KB, Tallant EA, et al. Effect of angiotensin-converting enzyme inhibition and angiotensin II receptor blockers on cardiac angiotensin-converting enzyme 2. Circulation 2005; 111: 26052610. https://doi.org/10.1161/CIRCULATIONAHA.104.510461.

48. Bavishi C, Maddox TM, Messerli FH. Coronavirus Disease 2019 (COVID-19) Infection and Renin Angiotensin System Blockers. JAMA Cardiology 2020; doi:10.1001/jamacardio.2020.1282. 